\title{
TECENDO RELATOS, VERSÕES E CENAS: ETNOGRAFIA DE UM EVENTO VIOLENTO ${ }^{1}$
}

\author{
Irme Salete Bonamigo \\ Universidade Comunitária Regional de Chapecó, Chapecó, Brasil
}

\begin{abstract}
RESUMO: A partir da etnografia de um evento e com base no referencial teórico-metodológico da Teoria do AtorRede, este artigo tem por objetivo abordar o tema violências na contemporaneidade, de modo a dar visibilidade à multiplicidade e à complexidade que envolve a sua discussão e a infinitude de variáveis em jogo. A "violência" é compreendida como efeito de redes compostas por elementos heterogêneos, híbridos de natureza-cultura, de humanos e não-humanos, do científico, do político, do afetivo e do tecnológico. Desta forma, a "violência" não se configura como ponto de partida, mas como ponto de chegada, como resultado de um processo que envolve mediadores em sua fabricação e que, além das práticas consideradas violentas, abrange as traduções da categoria, as inscrições dessas práticas e as estratégias de gestão e controle.
\end{abstract}

PALAVRAS-CHAVE: violências; teoria do ator-rede; etnografia; contemporaneidade; políticas públicas.

\section{WEAVING REPORTS, VERSIONS AND SCENES: ETNOGRAPHY OF A VIOLENT EVENT}

\begin{abstract}
Starting with the ethnography of an event and based upon the theoretic-methodological referential of the Actor-Network Theory, the aim of this article is to come close to the subject of violence in the contemporaneity, in such a way that may grant visibility to the multiplicity and complexity which involves its discussion and the infinitude of the variables at stake. "Violence" is understood as an effect of networks made up of heterogenic elements, nature-culture hybrids, of humans and no humans, of the scientific, the political, the affective and the technological. In this way, "violence" doesn't configure itself as a starting point, but as an arrival, as a result of a process that involves mediators in its own making and that, beyond the practices considered to be violent, comprises the translations of the category, the inscriptions of those practices and the strategies of management and control.
\end{abstract}

KEY-WORDS: violence, actor-network theory, ethnography, contemporaneity, public policies.

\section{Introdução}

O artigo discute o tema violências a partir do acompanhamento e análise de um evento violento, que envolve um furto cometido por uma criança e dois adolescentes e possibilita acompanhar a trajetória de Adilson (nome fictício), na época com 17 anos. O estudo deste evento fez parte da pesquisa etnográfica, que compôs a tese de doutorado Violências na Contemporaneidade: Etnografia de Redes Sociotécnicas na Cidade de Chapecó (SC), realizada por mim no período de 2004 a 2007, pelo Programa de Pós-Graduação em Psicologia Social (PPGPS) da UERJ.

Para evitar a redução da multiplicidade envolvida pelo evento, optei pelo referencial teórico-metodológico da Teoria do Ator-Rede (TAR) ${ }^{2}$, situada no campo da Sociologia das Ciências, tendo como principais fundadores: Bruno Latour, Michel Callon e John Law.

A Teoria do Ator-Rede permite seguir a construção e a fabricação dos fatos e acompanhar atores sem im- por-lhes uma definição anterior. Torna-se possível, através desta abordagem, descrever associações heterogêneas e os mecanismos de sua consolidação ou transformação, não reduzindo seus efeitos nem a um ator, nem a uma rede. Nesse sentido é possível desviar o foco da "violência"”3 com uma essência em si, e focar práticas, discursos, sentidos e inscrições contextualizados em um coletivo, constituído por humanos e não-humanos ${ }^{4}$. As violências podem ser pensadas, então, como resultado de diferentes formas de fabricação. Fabricação de práticas, de discursos, de significados e de inscrições. Dessa forma, durante a investigação, busquei abranger além das práticas violentas, o processo de inscrição dessas práticas, o processo de tradução da categoria violência e as estratégias de gestão que implicam tecnologias de vigilância e controle.

Rede é uma das noções centrais da Teoria do AtorRede e o seu uso permite evidenciar o hibridismo presente nas associações que se configuram: mistura entre hu- 
manos e não-humanos, sujeitos e objetos, natureza e cultura. A rede é uma estrutura composta de elementos em interação, marcada por uma forte heterogeneidade, e se caracteriza tanto pelo conjunto de relações entre pontos ou nós, quanto por conexões e agenciamentos internos, não possuindo limites externos. Sua abertura possibilita crescer para todos os lados e direções. Desta forma, seguir um evento que fosse considerado violento pelo coletivo tornou-se um dos caminhos possíveis para conhecer as redes tecidas em torno da "violência" em Chapecó, cenário do estudo, através do acompanhamento dos actantes que compõem a rede tecida que compõe a prática investigada a partir dos rumos tomados, dos encaminhamentos feitos e dos discursos elaborados e da historicização dos elementos que a constituíram.

O termo actante é empregado neste artigo, como sinônimo de ator, para dar ênfase também aos não-humanos vinculados a rede estudada. Um actante pode ser definido como qualquer pessoa, instituição ou coisa que tenha agência, que produza efeito no mundo (Latour, 2001). Por sua vez, o significado de evento é concebido, também com base em Latour (2001), como uma situação cujas circunstâncias são produzidas por humanos e não-humanos que se mesclam. A noção de evento põe em evidência a ação de todos os actantes, que produzem efeitos e sofrem as modificações deles advindas.

\section{Acompanhamento e Análise do Evento Violento}

\section{A Escolha do Evento}

Ao iniciar a coleta de dados, fiquei atenta aos comentários de habitantes de Chapecó e aos eventos veiculados pela mídia escrita e eletrônica com o objetivo de escolher um, que fosse considerado violento pelas pessoas da cidade, para acompanhar. Decidi selecionar para descrição algum evento vinculado ao cotidiano da cidade. Surgiram possibilidades como: acidente de trânsito, homicídio, abuso sexual, agressão sofrida no espaço familiar, furtos e roubos, as quais poderiam conduzir-me a diferentes redes. Como frequientemente eu assistia nos noticiários das TVs locais, lia em reportagens de jornais, ouvia discursos de policiais e comentários de diferentes pessoas sobre furtos e roubos cometidos por adolescentes, vinculados à categoria violência, optei por fazer a etnografia de um evento que os envolvesse e o elegi a partir da seguinte reportagem, publicada em um jornal local:

Menores detidos com produtos furtados - Chapecó - dois adolescentes, sendo um de 17 anos e outro de 13 anos, em companhia de uma criança de 7 anos, foram detidos na madrugada de segunda-feira pela Polícia Militar. Com eles os policiais encontraram várias peças de roupas, de modelos diversos. Eles estavam com 24 calças jeans, 8 jaquetas sarja, 14 moletons e 6 cabides. Conforme informações da PM, as roupas haviam sido furtadas em uma loja instalada na Avenida Getúlio Vargas, no centro de Chapecó. Para terem acesso ao interior do estabelecimento comercial, os menores de idade arrombaram uma grade de proteção e após quebraram um dos vidros. (Diário do Iguaçu, 17/05/2005).

Feita a escolha, tratava-se, então, de abrir a caixapreta da reportagem para fazer surgir o evento em toda a sua multiplicidade. No lugar de focar a polarização ladrão/ vítima tornava-se necessário abordar as mediações, conhecer a rede de actantes que permite olhar para as diversas conexões e efeitos que possibilitam relações e práticas.

Comecei seguindo as pistas divulgadas pela reportagem, busquei os registros da ocorrência na Polícia Militar e Polícia Civil, os quais me permitiram acessar informações e identificar actantes para as entrevistas. A coleta dos indicadores para a descrição do evento me levou a conhecer a trajetória do adolescente Adilson, de 17 anos, que por sua vez me conduziu à rede de programas e estabelecimentos voltados para adolescentes em conflito com a lei.

\section{A Rede Composta pelo Evento}

As primeiras entrevistas e documentos pesquisados permitiram descrever o evento, a partir de uma seqüência inicial:

Antes $=>$ alarme de loja dispara e aciona $=>$ a Empresa de Segurança $U$ => o vigilante da empresa de segurança dirige-se ao local e aciona $=>$ o Centro de Operações da Polícia Militar $(\mathrm{COPOM})=>$ que faz o registro do evento (Boletim de Ocorrências [BO]) e aciona => uma viatura: guarnição com policiais militares $=>$ que faz a detenção da criança e adolescentes $=>$ o vigilante aciona empresária (loja furtada) => a empresária chega à loja $\Rightarrow>$ a Polícia Militar conduz a criança e adolescentes à Central de Polícia Civil => a empresária dirige-se à Central de Polícia Civil $=>$ o delegado e a escrivã fazem o registro do Boletim de Ocorrência Circunstancial $\Rightarrow>$ a Mãe do adolescente de 17 anos (Adilson) chega, após ser avisada pela Polícia Militar e faz a assinatura do Termo de Responsabilidade pelos adolescentes $=>$ a criança é encaminhada ao Conselho Tutelar $=>$ os adolescentes são encaminhados ao Poder Judiciário (Vara da Família, Órfãos, Infância e Juventude) => depois.

As categorias antes e depois serviram para localizar o evento e buscar a descrição do percurso da criança e adolescentes antes, durante e depois do episódio. No entanto, neste artigo será abordada apenas a trajetória de Adilson.

Como se pode perceber, o evento envolveu uma rede de actantes: criança de 7 anos (CA), adolescente de 13 anos (ME), adolescente de 17 anos (Adilson), edifício 
em construção, loja de roupas infanto-juvenil, dispositivo de alarme que dispara, vigilante de empresa de segurança, proprietária da loja, COPOM, artigo 155 do Código Penal, Boletim de Ocorrência, policiais militares, escrivã, delegado, Boletim de Ocorrência Circunstancial, mãe de Adilson (MA), Termo de Responsabilidade, Conselho Tutelar e Vara da Família, Órfãos, Infância e Juventude. Mas, como interagem esses actantes?

Latour (2006, p. 292-295) contribui com essa discussão ao chamar a atenção para o modo como se dá a interação face a face dos actantes: (a) nenhuma relação local é isotópica, ou seja, aquilo que age no mesmo momento em um determinado lugar provém de numerosos outros lugares, de numerosos outros momentos e de actantes heterogêneos; (b) nenhuma interação é sincrônica, pois a temporalidade dos actantes é múltipla, com idades e ritmos diferentes; (c) as interações não são sinópticas: em um curso de ação, apenas algumas entidades são visíveis em um dado momento, portanto não podemos listar todos os actantes de uma cena, pois não é possível realçá-los ao mesmo tempo, já que são numerosos demais e fazem parte de maquinarias complicadas, que se tornam invisíveis em certos momentos quando cumprem o papel de intermediário; (d) as interações não são homogêneas, pois há uma diversidade de participantes, feitos de qualidade diferentes de materiais, que contribuem com o desenrolar da ação e (e) as interações não são isobáricas, ou seja, alguns participantes impõem a sua presença com força, exercendo pressão sobre os demais, enquanto que outros não têm visibilidade. No entanto, as situações podem mudar rapidamente e de forma inesperada e, então, a distribuição dos actantes no primeiro e segundo plano se modifica também: os actantes invisíveis tornam-se visíveis e vice-versa.

Ao longo da descrição do evento, teremos a oportunidade de observar as diferenças entre os actantes em sua interação: os múltiplos lugares do onde provêm, as suas diversas temporalidades e ritmos, as qualidades dos materiais de que são feitos e as diferentes pressões que as suas presenças exercem sobre outros actantes. Além dos actantes já listados, com conexões visíveis nesse primeiro momento, há a presença de outros que ainda não aparecem aqui, mas também contribuíram para produzir o evento e que a descrição do antes e depois tornarão visíveis num segundo momento.

\section{O Furto}

Segundo Adilson, o evento ocorreu da seguinte maneira: ele e dois amigos dormiam em um prédio em construção abandonado e resolveram arrombar a loja que dava de fundos para o mesmo. Adilson, com uma barra de ferro, "estourou" três barrinhas, também de ferro, que davam acesso a loja, quebrou o vidro e entrou, dis- parando o alarme. O vigilante da Empresa de Segurança que fazia o monitoramento eletrônico da loja chegou e eles foram para o porão com a mercadoria (roupas) para se esconderem. No porão havia ferro e madeira produzindo ruído e chamando a atenção do vigilante, o qual chamou a Polícia Militar, que com o auxílio de lanternas os encontraram e os levaram para a Central de Plantão da Polícia Civil, na qual foram autuados em flagrante no artigo 155 .

O Boletim de Ocorrências da Polícia Militar classifica o furto através de tipo (furto a estabelecimento comercial), data, local da ocorrência, pessoas envolvidas, guarnições empregadas na ocorrência e histórico da ocorrência.

As versões do furto ressaltam a presença de mais alguns elementos actantes do evento, além dos acima já listados: (a) na configuração do furto: dormir em prédio abandonado, constituir um grupo, presença de barra de ferro e vidro quebrável, espaço para esconder-se e esconder a mercadoria; (b) na tentativa de evitar o furto: grade de proteção, lanterna com luz forte, presença de material que produz barulho (madeira e ferro).

\section{O Encontro entre Adilson, o Vigilante e os Policiais Militares}

Segundo Adilson, o seu contato com o vigilante se deu da seguinte forma: "Conversar eu não falei nada, porque ele ameaçou de me levar lá na ponte do Goio-ÊEn ${ }^{5}$ e me jogar lá de cima. Só porque eu era o maior. $\mathrm{O}$ vigilante não me encostou um dedo, só isso que me aconteceu". Com os policiais militares foi diferente:

Como eu era o maior eles me surraram bastante lá embaixo, antes de me jogarem por cima do portão. Eles me bateram com um pedaço de manga ${ }^{6}$. Eles me algemaram com as mãos para trás e me jogaram por cima do portão. Daí eu cai lá e o outro policial me juntou no tapa, daí me jogaram dentro da viatura e aí não deixaram me bater. (Adilson).

O relato de Adilson coloca em evidência os actantes "ameaça" e "agressão física" vinculados às providências tomadas após a tentativa de furto. É inevitável questionar a pressão exercida por esses actantes, tanto na configuração desse evento, como de eventos passados e futuros.

\section{Na Central de Plantão da Polícia Civil (CPP)}

Na CPP foi feito o Boletim de Ocorrência Circunstancial, no qual foi inscrito o evento através das declarações de Adilson e ME e da autuação. A inscrição do evento, primeiro no Boletim de Ocorrência da Polícia Militar e depois no Boletim de Ocorrência Circunstancial da Polícia Civil, sendo transformado em texto de um documento, permitiu que o mesmo pudesse ser transportado para outros lugares (como a mídia e o Poder 
Judiciário), mantendo-o estável e permitindo combinar com outras categorias e outros registros. Para Latour (2004, p. 45), "os textos agem sobre o mundo, e circulam em redes práticas e instituições que nos ligam a situações".

Pode-se considerar também que a inscrição do evento é uma forma de tradução do mesmo, possibilitando ainda outras traduções em sua circulação, por exemplo, pela mídia. O processo de tradução implica transformação e permite novas interpretações a partir de diferentes interesses.

\section{O Evento se Transforma em Reportagem de Página Policial de Um Jornal}

Qual o caminho percorrido pelo evento para transformar-se em reportagem na página policial do Diário do Iguaçu? Segundo a Actante $\mathrm{K}^{7}$, as polícias de Chapecó (civil, militar e federal) enviam aos jornais a lista de ocorrências duas vezes ao dia. No jornal é selecionado "o que é interessante das pessoas saberem. ... uma batidinha de carro na esquina ... não é muito interessante, mas quando você não tem nada e precisa completar a página você a transforma também numa matéria" (Actante K).

Nos Boletins de ocorrências enviados aos jornais não consta todos os dados registrados nas polícias: " $O$ boletim ele vem com iniciais e a polícia também não fornece placas dos carros, a pessoa quando vai registrar a ocorrência de um acidente ou de um roubo, ela tem o direito de pedir para não ser divulgado, daí a polícia não divulga" (Actante K). Com base nesses dados é composta a matéria. A editoração da página policial envolve a seleção das matérias que são consideradas mais relevantes, sendo escolhidas pelo grau de gravidade: " $u m$ acidente com morte, um seqüestro, um estupro, tipo de assalto" (Actante K). Apesar do evento em estudo não caracterizar grau de gravidade, já que não foi finalizado e não envolveu morte, apresenta outros elementos interessantes para a mídia, como o envolvimento de uma criança de 7 anos, junto com dois outros adolescentes, a apreensão dos mesmos, os danos provocados na loja e o tipo de mercadoria roubada.

A mídia é um dos actantes que produz efeitos na configuração do evento, pois em sua elaboração e circulação, na forma como ressalta ou não elementos, produz formas de pensar, sentir e perceber o evento e a "violência" da cidade. Pode-se perceber que, na forma da escrita e veiculação, estão presentes a formatação das polícias e a tradução do repórter e editor da página, focando apenas alguns elementos, deixando outros de lado, como as questões históricas e sociotécnicas que envolvem tanto a polícia como os autores de atos infracionais que poderiam fazer emergir a multiplicidade presente.
A Compreensão do Evento pela Vítima do Furto

AActante F relata que foi a quarta vez que a loja foi furtada e todas às vezes com envolvimento de "menores", mas registrou queixa apenas duas vezes. Considera que a polícia faz além do que pode, mas a lei não está sendo colocada em prática pelo Ministério Público e pelo Governo, pois há superlotação tanto no presídio quanto na penitenciária, o que impede a prisão de alguns criminosos.

F considera que o problema está nas famílias e avalia que a solução seria o controle do índice de natalidade: lei rígida e laqueadura gratuita. "É não colocar filho no mundo sem condições, depois ficam na rua, não são cuidados" (Actante F). Pode-se perceber que, na compreensão do evento, $\mathrm{F}$ aponta alguns actantes determinantes do evento: polícia, governo (e suas instâncias), crianças e adolescentes pobres, famílias e rua. Entretanto, a sua avaliação reduziu a rede, que, como vimos, é extensa, a dois elementos: concentrou na família a força para desencadear o evento e no governo a força para evitá-lo, através de uma medida extrema: controlar o índice de natalidade.

\section{O Encontro de Adilson com a Sua Mãe (MA) na Central de Polícia}

$\mathrm{Na}$ Central de Polícia, Adilson encontrou-se com a sua mãe e segundo ele: "A mãe falou um monte, disse que não era para aprontar mais porque não adianta: 'porque que você vai roubar, se você tem o que comer em casa, se não falta nada?"' MA relata que quando chegou à Central de Polícia assinou o termo de responsabilidade para o Adilson e o outro adolescente e então eles foram soltos. Mas o Adilson não foi para casa, "ele foi para o centro de novo", o que gerou preocupação em MA:

muitas vezes eu pensava de noite: 'Ah meu Deus o Adilson... Às vezes tiros por aí, a polícia, meu Deus será que o Adilson veio com roubo para cá?' Porque aqui ele não trazia, ele sabia que nós não aceitávamos, então ele não trazia roubo ... Só que levava lá para os traficantes [para comprar droga]. Então, era uma preocupação ... ou podia morrer dentro de uma casa roubando, ou podiam matá-lo lá fora, roubando um carro, qualquer coisa, então ele estava sempre em perigo (Actante MA).

A partir dos relatos de Adilson e MA, sobressaemse novos actantes na configuração do evento: a droga, o traficante, a rua e a mercadoria furtada.

\section{Adilson é Encaminhado ao Poder Judiciário de Santa Catarina}

A leitura do processo de Adilson no Poder Judiciário me permitiu conhecer a sua trajetória inscrita nesse órgão. Em sua lista de atos infracionais estavam inscritos trinta e seis furtos (sete em veículos, seis em estabeleci- 
mentos comerciais e vinte e três não especificados), seis tentativas de furto, dois arrombamentos com furto, três danos materiais, dois portes de arma branca, uma posse de droga e duas perturbações. $\mathrm{O}$ evento em estudo estava relatado no processo, assim como o relato de que Adilson não compareceu à audiência marcada, o que levou o promotor e o juiz a intimar o adolescente e sua família a uma outra audiência.

No processo de Adilson também estavam inscritos os encaminhamentos feitos pelo Poder Judiciário diante do seu envolvimento em práticas ilícitas, conforme citado na descrição das infrações. Esse registro possibilitou visualizar a rede de programas e de organizações voltados para os adolescentes autores de atos infracionais, em Chapecó, e me conduziu a percorrer os estabelecimentos buscando conhecê-los, assim como conhecer a passagem de Adilson em cada um deles. Esses estabelecimentos são aqui também concebidos como actantes tanto do evento em descrição quanto da rede na qual circula Adilson, pois participaram da rede de relações de Adilson, produzindo algum efeito na configuração do furto.

\section{Adilson e Sua Rede de Relações}

Além da rede que configura o evento em estudo, começa a delinear-se a rede de relações, na qual circula Adilson, rede que até o momento conecta os elementos: família, escola, droga, traficante, rua, mercadoria furtada, polícias, empresa de segurança, outros adolescentes, estabelecimentos para adolescentes em conflito com a lei. Ainda há outros elementos que se tornarão visíveis gradativamente.

Cabe esclarecer que a concepção de indivíduo que permeia este estudo é de "uma rede auto-referente, a qual regenera continuamente por suas interações e transformações a rede que o produziu, e se constitui como sistema ou unidade concreta no espaço em que existe, especificando o domínio topológico no qual existe como rede" (Parente, 2004, p. 106). Dessa forma, a subjetividade é uma dimensão que co-emerge com os universos sociotécnicos. O saber, a razão, a cognição, a inteligência são faculdades "que co-emergem com o indivíduo em um processo de auto-engendramento" e, portanto "não devem ser vinculados apenas a seu cérebro, mas o seu corpo, que ultrapassa de longe o seu invólucro corporal e se estende até onde se estendem suas redes sociotécnicas, seus hábitos, seus apegos" (Parente, 2004, p. 106), incluindo os não-humanos a eles articulados.

Compreender, então, as ações de Adilson - actante do evento em estudo - significa compreender a rede na qual ele transita e os elementos que a constituem, observar o que esta rede faz-fazer, o modo como ele afeta e é afetado por ela. A seguir, serão descritos alguns actantes que compõe esta rede e alguns dos efeitos produzidos pelos mesmos.

\section{A Família}

A família de Adilson era composta por: Adilson, Mãe (MA), três irmãos (NA,TO e SE) e duas irmãs (NE e DA). O pai (PO) morreu atropelado quando Adilson tinha 12 anos.

MA, mãe de Adilson, veio morar em Chapecó, com sua família (mãe e 7 irmãos), quando tinha 9 anos de idade, há 36 anos atrás. Antes, a família morava em Erechim (RS) e trabalhava com agricultura. A mudança de cidade foi provocada pela situação do pai tê-los abandonado, foi para o Paraguai e constituiu outra família. $\mathrm{O}$ afastamento do pai estimulou o abandono da agricultura e o deslocamento para Chapecó.

MA começou a trabalhar de babá quando tinha 13 anos, após trabalhou de empregada doméstica, como faxineira em empresa, em escola e como diarista, fazendo limpeza doméstica. Em época de eleição política já trabalhou também distribuindo folhetos e solicitando votos para candidatos.

PO, pai de Adilson, morava em Xaxim (SC) ${ }^{9}$ com sua família, em terreno irregular, quando foi despejado pelo governo municipal. Em Chapecó, PO começou a trabalhar como pedreiro em uma imobiliária e se manteve no emprego durante 18 anos, até o seu falecimento.

A vinda das famílias de MA e PO a Chapecó está vinculada à perspectiva de trabalho e moradia. Na época, a cidade estava em pleno crescimento possibilitando oportunidade de trabalho e habitação às pessoas que ali chegavam.

Com relação à escolarização, a mãe de MA era analfabeta e o pai semi-analfabeto. PO teve como escolarização o Ensino Fundamental, assim como MA e seus irmãos.

Quanto à relação familiar, Adilson descreve a relação com o seu pai: "Meu pai para mim era tudo, perdi o meu pai daí comecei a fazer anarquia, comecei a roubar, cheirar cola, fumar maconha, crack, cocaína e assim por diante". Segundo MA, o pai de Adilson "estava sempre em casa, não bebia ... e nós saíamos todos juntos, ele era evangélico, nós também somos da Cadeia da Prece, e daí o Adilson se revoltou muito, não sei o que foi que virou".

Adilson e MA referem o falecimento do pai como um marco na vida de Adilson, que o deslocou, a partir de conexões com outros elementos, para trilhar caminhos não previstos. No entanto, o parecer psicológico de um dos estabelecimentos onde Adilson ficou internado traduz as informações, estabelecendo outro sentido: "Adilson vive em um mundo de fantasia, atribui os seus problemas à morte do pai, sente-se desamparado e ao mesmo tempo demonstra insegurança e fracasso diante dos fatos que acontecem em sua vida".

Arelação de Adilson com a mãe foi narrada por eles como permeada por situações de apoio e ao mesmo tempo de conflitos e decepções frente às situaçõos vividas. Adilson referiu-se à mãe como alguém que lhe dá conselhos, sen- 
do uma figura de apoio nos momentos difíceis. MA afirmou ter vivido muitas situações difíceis com Adilson, em diferentes momentos da vida, sentindo-se impotente, sem saber o que fazer para ajudá-lo. MA relatou também situações nas quais foi culpabilizada por pessoas ligadas a programas e estabelecimentos aos quais Adilson estava vinculado, como a afirmação de que alguma coisa faltou para ele e a de que não conseguia controlá-lo.

MA narrou, também, ter recebido a ajuda de suas filhas, NE e DA, para encaminhar os outros filhos. Como na situação na qual descobriu que Adilson e NA estavam faltando à escola e indo para o centro da cidade: "daí eu liguei para a minha filha em Florianópolis ... e disse: 'DA, eu vou comprar uma passagem e vou mandar o NA morar com você. $O$ Adilson fica sozinho aqui, eu vou dar um jeito no Adilson aqui'. Segundo MA, na ocasião da entrevista, NA ainda estava em Florianópolis, estudando e trabalhando: "trabalha em um shopping, junto com meu cunhado, estuda, está beleza, quero que tu vejas, vai vir no fim do ano para cá para visitar".

Como veremos adiante, Adilson também foi auxiliado pela irmã NE, tendo morado 3 meses com ela em Balneário Camboriú, em 2005. Segundo MA, a mudança de lugar e o acesso a outras possibilidades de trabalho e escola contribui para mudar o comportamento dos filhos. O parecer elaborado por um dos estabelecimentos, no qual Adilson foi internado, traduziu a atitude da mãe a partir de uma outra versão: "A mãe demonstra claramente que não tem controle sobre os filhos, pois dois irmãos de Adilson mais novos, moram com suas irmãs casadas porque a mãe não consegue fazer a vida deles".

As duas versões levam a diferentes compreensões da ação. Na versão da mãe, enviar os filhos para ficarem com as irmãs em outra cidade está relacionado à sua percepção da necessidade de excluí-los da rede na qual eles transitavam, rede forte que a fazia perceber-se como incapaz de disputar os filhos com a mesma, pois não tinha vínculos suficientes para possibilitar inserção em outras redes. Para "controlar" os filhos teria que "controlar" a rede que se mostrava poderosa. $\mathrm{Na}$ versão do parecer, a ação dos filhos de inserir-se em um trabalho, freqüentar a escola e não se envolver em confusão dependeria do "controle" da mãe.

\section{A Escola}

O percurso de Adilson na escola foi permeado por muitas faltas, abandono e reprovação. Estudou em uma escola básica municipal de Chapecó. Iniciou a primeira série em 1995, com 8 anos, mas reprovou por faltas, concluindo a série no final de 1996. Na segunda série em 1997 também reprovou. Em 1998, 1999 e 2000 abandonou a escola, após alguns períodos de frequiência. Em 2001 voltou a estudar sendo inserido em uma sala de progressão ${ }^{10}$ por causa da idade (14 anos), mas abando- nou a escola. Retomou os estudos no Centro de Educação Regional em 2004, quando estava internado, freqüentando aulas de nivelamento (Ensino Fundamental) do Centro de Educação de Jovens e Adultos, durante 7 meses.

Segundo MA, Adilson abandonou a escola, após a morte do pai: "ele ficou revoltado, não sei o que deu nele, não quis mais ir ao colégio, ... arrumou uma caixinha para engraxar, ia para a cidade e ia hoje e não vinha mais hoje, só vinha amanhã e começou uma folia" .

Adilson relatou que gostava da escola devido às amizades que tinha, no entanto tinha dificuldades com uma professora:

um dia eu me cansei dela, ela quis me chamar a atenção lá e ela veio com uma régua daquelas de madeira na mão e quis dar uma reguada em cima dos meus dedos, eu saí para trás peguei a cadeira e taquei nela. Ela fez um berreiro diante da sala de aula e eu saí para fora do colégio e não voltei mais.

Nos documentos da escola, Adilson é descrito como um aluno que falta bastante, mas "tem bom relacionamento com o grupo, é organizado, não fala muito, fica quieto (parece não dormir durante a noite) e ... tem dificuldade em todas as áreas de conhecimento”. Há o relato de quatro visitas que a escola fez à casa de Adilson, conversas com a mãe e a observação, de que após as visitas ele voltava a comparecer durante dois dias e depois continuava faltando.

\section{A Droga}

Adilson mencionou ter feito uso de várias drogas (cola, maconha, cocaína e crack), mas destacou fazer uso em especial e com maior freqüência do crack. Durante as entrevistas, Adilson, na compreensão da sua vinculação com o crack, oscilou ora apontando o crack como mantenedor do domínio da relação, não conseguindo desvencilhar-se dele e sendo levado a praticar furtos para poder obtê-lo e ora afirmando a sua possibilidade de manter o domínio da situação, afastando-se da droga.

No entanto, Latour $(2000,2001)$ sugere olhar não somente para a droga, nem somente para a pessoa, mas para a relação pessoa-droga, pois nem a pessoa domina a droga, nem é dominada por ela, mas constitui-se um processo de "faz-fazer", no qual não cabe estabelecer causalidade, pois ninguém age simplesmente. Torna-se importante, então, não focar o sujeito ou o objeto, mas o que proporciona o vínculo, a forma como os dois são afetados e os efeitos desse vínculo. Também não se pode antecipadamente prever o que vai acontecer quando se junta uma pessoa e uma droga, pois não há uma determinada essência do sujeito ou do objeto, os objetivos do sujeito e do objeto não estão fixados. A ação farmacológica da droga e o estado da pessoa, suas condições e expecta- 
tivas, sofrem modificações no encontro pessoa-droga e um novo objetivo pode ser constituído, havendo a criação de um novo vínculo que modifica tanto a pessoa quanto a droga.

\section{A Rua}

Conforme mencionado anteriormente, Adilson começou a ficar na rua quando tinha 12 anos de idade, começando também, nesse período, a trabalhar de engraxate, utilizar drogas, a furtar e a freqüentar estabelecimentos e programas direcionados para crianças e adolescentes em situação de rua e autores de ato infracional. Arua é descrita por Adilson como um espaço de liberdade: "Eu preferia $a$ rua, porque na rua eu estava mais na liberdade". Mesmo associando a rua com liberdade, Adilson também se recrimina pela atitude de permanecer nela: "Eu tenho minha família, não preciso estar pedindo pão seco em casa de ninguém, eu tenho o que comer em casa, só estou parando na rua mesmo porque eu sou um idiota ..., tenho mãe, tenho irmão". Quando perguntei sobre as lembranças que guardava da rua, Adilson respondeu: "A única coisa que guardo de lembranças da rua é que vivia roubando também, vivia dormindo debaixo dos papelões, debaixo dos edifícios, eram mal construídos e ficavam, a gente tomava conta do lugar, bem dizer ali era nosso lar". Cabe observar que a rua é associada também ao grupo, à presença de outros adolescentes.

\section{O Traficante}

O furto vincula-se ao tráfico, pois os traficantes trocam as mercadorias roubadas por droga: "eles entram em uma casa, roubam o que vem na frente, para poder comprar droga, porque o traficante não vende fiado, o traficante vai querer dinheiro, então ele faz uma troca, um calçado, uma roupa, uma televisão, qualquer coisa" (Actante MA).

Segundo Adilson e MA, os furtos de Adilson foram sempre associados à compra de droga: "ele trocava por droga, porque às vezes não tinha dinheiro. Traficante não dá, de graça ninguém dá. Dá, mas daí você fica com aquela dívida e se não pagar, matam". MA relata situações, nas quais Adilson roubou coisas da sua própria casa para trocar por drogas.

Segundo Adorno (2005), as práticas vinculadas ao narcotráfico no Brasil, antes concentradas nas capitais, estão se expandindo para as cidades do interior do Brasil porque encontram nas mesmas os atores que necessitam para a sua constituição: (a) um mercado de consumo, com pessoas em busca de novas experiências sociais e dispondo de meios suficientes para comprar a droga; (b) cidadãos empobrecidos, sem trabalho ou sem perspectiva de futuro, suscetíveis de serem atraídos para diversas atividades, como o controle de pontos de distribuição de drogas, pontos de venda, pontos de circulação de dinheiro ou de dívidas contraídas por consumidores ou pequenos revendedores; (c) a possibilidade de formação de uma rede de comércio ilícito ligando pequenos comerciantes e empresários situados em segmentos diversificados do mercado e segmentos do poder público. $\mathrm{O}$ autor analisa que os benefícios do comércio ilícito geralmente servem ao financiamento de campanhas eleitorais e à manutenção de um amplo conjunto de lobistas, intermediários, comerciantes e profissionais dotados de uma ampla influencia sobre os indivíduos, os quais são incumbidos de tomar decisões implicando a utilização de fundos públicos.

Adorno (2005) observa traços importantes do funcionamento do narcotráfico em outras cidades médias do Brasil, que podem ser utilizados para mapear possíveis actantes do narcotráfico de Chapecó, principalmente porque estudos mostram que suas redes são extensas, ultrapassando a fronteira do município, do estado e do país. No entanto, conhecer o narcotráfico de Chapecó implicaria efetivamente conhecer o trabalho dos atores que cotidianamente fabricam o seu mercado, o que não foi possível nessa pesquisa. Concebo mercado como uma construção sociotécnica, com base em Callon (2004, p. 75): "O mercado é uma construção e reconstrução permanente, é uma construção coletiva que supõe negociações, interações e aprendizados".

\section{A Mercadoria Furtada}

Além dos traficantes, que trocam a mercadoria roubada por drogas, há em Chapecó pessoas que fazem a receptação das mesmas: "Há 10 a 15 receptadores em Chapecó que financiam os furtos e roubos, pagam advogados para tirar da cadeia, que dizem: 'eu compro de você'. A empresa de segurança sabe, a polícia sabe, mas não conseguem incriminar". (Actante $\mathrm{S}$ ).

A mercadoria furtada é um actante presente na rede de relações de Adilson, que medeia principalmente a sua vinculação com a droga e estabelecimentos para adolescentes em conflito com a lei. Segundo Adilson, deixar de roubar requer um grande esforço pessoal e a fabricação de uma nova rede de relações que envolva outros actantes: "Arrumar um emprego, arrumar uma mulher e quem sabe ter um filho, uma casa e parar de aprontar de uma vez".

\section{O Percurso de Adilson por Estabelecimentos e Programas}

A trajetória de Adilson conectou-se aos seguintes estabelecimentos e programas para crianças e adolescentes: Conselho Tutelar (CT), Centro de Internamento Provisório (CIP), Centro de Educação Regional (CER), Programa de Liberdade Assistida Comunitária (LAC), Casa da Acolhida e Prestação de Serviço à Comunidade (PSC). Os estabelecimentos e programas baseiam-se no Estatuto da Criança e do Adolescente (ECA) e têm por finalida- 
de proteger a criança e o adolescente e aplicar medidas sócioeducativas, sem caráter punitivo, como forma de reinserção social através do fortalecimento dos vínculos familiares e comunitários.

Adilson começou a sua trajetória de passagem por estabelecimentos e programas, com 12 anos de idade e sua entrada se deu através do Conselho Tutelar, onde sua história passou a ser inscrita em documentos, que traduziram a sua vinculação com o estabelecimento. Os registros dos atendimentos são breves e referem-se a furtos cometidos pelo adolescente e encaminhamentos feitos pelo CT, como "encaminhamento aos pais ou responsável mediante termo de responsabilidade" e acompanhamento de Adilson à delegacia para depoimento.

A vinculação de Adilson com o Centro de Internamento Provisório (CIP) abrangeu o período de novembro de 2001 a maio de 2004 e envolveu cinco internações de tempos variáveis de um dia a três meses. O CIP é um estabelecimento destinado a adolescentes de 12 a 18 anos incompletos, de ambos os sexos, autores de ato infracional, sendo decretado pelo Poder Judiciário o internamento provisório de até 45 dias (no caso de Adilson esta norma não foi respeitada, pois em uma das internações permaneceu durante 3 meses).

Adilson também ficou internado, de maio a dezembro de 2004, no Centro de Educação Regional (CER), que tem por finalidade "atender, por determinação judicial, em regime de internação, adolescentes do sexo masculino autores de Ato Infracional de acordo com o artigo 122 do Estatuto da Criança e do Adolescente, tendo como principal objetivo o resgate da cidadania" (CER, 2005, p. 1).

Adilson chegou ao Programa de Liberdade assistida Comunitária (LAC) em dezembro de 2004, após a sua saída do CER, para dar continuidade ao seu processo sócio-educativo, no entanto não manteve sua vinculação com o programa. O LAC é uma medida determinada judicialmente, onde o adolescente é acompanhado por um orientador comunitário residente em uma determinada Regional de Assistência Social. O objetivo do programa é inserir o adolescente socialmente, na escola e na família para que não reincida no ato infracional e incluí-lo em cursos profissionalizantes (Prefeitura Municipal de Chapecó, 2003).

A Casa da Acolhida, segundo a Prefeitura Municipal de Chapecó (2003, p. 6), "é um espaço de acolhimento com atendimento psicológico, social e pedagógico às crianças e adolescentes em trajetória de rua e drogadição". A passagem de Adilson na Casa da Acolhida caracterizou-se por entradas e saídas freqüentes do estabelecimento e segundo Adilson não tiveram bons efeitos para ele por que, apesar das regras, a droga entrava no estabelecimento.
A medida Prestação de Serviço à Comunidade (PSC) foi aplicada diversas vezes a Adilson, no entanto ele não as cumpriu: "nunca cumpri, vinha os papéis para eu comparecer, eu ia um dia e não ia mais, nunca paguei PSC, porque eu não parava nos lugares, batia a vontade de usar droga eu saía, não voltava". Segundo o Estatuto da Criança e do Adolescente, ECA (1998, p. 25-26), o PSC é uma medida sócio-educativa, que "consiste na realização de tarefas gratuitas de interesse geral, por período não excedente a 6 meses, junto a entidades assistenciais, hospitais, escolas e outros estabelecimentos congêneres, bem como em programas comunitários e governamentais".

Os estabelecimentos e programas que fizeram parte da trajetória de Adilson, conforme o ECA, busca proteger a criança e o adolescente de forma a reinseri-los socialmente através do fortalecimento dos vínculos familiares e comunitários. No entanto, através do percurso de Adílson, detectou-se a produção de efeitos não previstos: sensação de desamparo, vigilância, punição, vivência de situações de conflito, competição e hierarquia com outros adolescentes, dentre outros. Observam-se como recorrentes as atitudes de Adilson não permanecer na Casa da Acolhida, não cumprir as medidas de PSC e LAC e não comparecer à audiência com o juiz, o que gerou por duas vezes internação no CIP. A sua justificativa durante as entrevistas, era que isso acontecia devido a sua relação com a droga, que o deslocava para circular na rede que, como vimos anteriormente, conecta também os elementos: traficante, mercadoria roubada, rua, família, as polícias, empresas de segurança e também os estabelecimentos, que então passam a fazer parte dessa rede.

Segundo Latour (2000) vínculo é o que afeta e coloca em movimento. Quanto mais vínculos, mais possibilidades o actante terá de circular pela rede. Um bom vínculo é o que proporciona possibilidades inesperadas, situações novas, criativas, interessantes.

É interessante observar que os estabelecimentos visavam vincular Adilson em uma outra rede, composta pelos actantes: escola, comunidade, família, local de cumprimento da medida (tarefas, oficinas, recreação, diploma profissionalizante, pessoas), atendimento psicológico, etc. No entanto, seus efeitos parecem ter fortalecido ainda mais a rede na qual Adilson circulava, pois a atitude de furto, de uso de droga, de estar na rua se manteve e se intensificou ao ponto de Adilson ser vinculado ao presídio, quando completou 18 anos.

\section{Empresas Privadas de Segurança}

Como vimos, uma empresa privada de segurança foi um dos actantes do evento em estudo, que ao detectar o furto acionou a Polícia Militar. Segundo Actante S, vinculado a uma empresa de segurança: "é comum ter esses moleques no centro da cidade, conhecidíssimos, vão roubar em algum lugar, chama-se a polícia, a polícia 
leva às vezes, ou aborda e pede para ir para casa e em seguida mesmo eles acabam roubando".

\section{A Maioridade de Adilson e a Sua Passagem pelo Presídio Regional de Chapecó}

Na ocasião da realização da primeira entrevista com Adilson e sua mãe, em julho de 2005, Adilson estava preso no Presídio Regional de Chapecó, com base no artigo 155 do Código Penal, devido a um furto de roupas, cometido com outros dois jovens. Adilson foi condenado a 2 anos de prisão, mas foi liberado após 6 meses de cumprimento da pena, não chegando a ir para a penitenciária. Quando saiu do presídio foi morar com a irmã, residente em Balneário Camboriú e começou a trabalhar em um Shopping, com carteira assinada, auxiliando na coleta de lixo. E, então, quando recebeu o salário do segundo mês, no caminho para casa acabou parando na praia e usando droga, o que consumiu, naquela noite, além do seu salário, o tênis e a roupa que usava. Esta ocorrência culminou na volta de Adilson para Chapecó e o seu retorno ao presídio: "Foi pior ainda, aqui eu conheço tudo, eu sei tudo onde são os pontos do tráfico aqui em Chapecó. ... Cheguei aqui e comecei a furtar, a usar droga e daí deu no que deu, vim parar até na cadeia".

A existência de uma rede que faz-fazer, mencionada anteriormente, torna-se aqui mais clara. São os vínculos que possibilitam a circulação pela rede. E o presídio tornou-se também actante da rede, ao permitir a criação e ampliação de vínculos: "o cara entra na cadeia e descobre qual é o empresário que compra o pequeno furto, quem é o grande praticante que o tornará uma 'mula', quem é que te explora no tipo de coisa, etc." (Actante RP).

\section{Considerações Finais}

Teria muitas formas de descrever o evento, pois como sugere Latour (2006, p. 217), "não há informação, apenas transformação", sendo a descrição uma forma de tradução e toda tradução implica também em traição, pois envolve similaridades e diferenças. A narrativa do evento foi composta de fragmentos, de pequenas histórias, de cenas e diálogos com oscilações e ambivalências; pois, segundo Law (1999), um estudo ator-rede não pode ser narrado numa única e coerente forma, como uma história completa e total, mas sim "abraçar uma arte de descrever os padrões e texturas que formam um remendo intelectual" (p. 8), uma série de retalhos que se ligam. Eé importante deixar claro que a narrativa, a descrição não se refere a alguma coisa que já estava lá, mas o próprio movimento de narrar e descrever produz realidades e as conexões entre essas realidades.

Seguir um evento do cotidiano, sem aparente gravidade, me levou às cenas, relatos e versões que possibi- litaram apreender um pouco da multiplicidade que abarca tanto as práticas violentas como a gestão da "violência" e deram visibilidade a outros eventos, dos quais muitos podem ser considerados graves, já que envolvem sofrimento, agressão e corrupção. $\mathrm{O}$ evento que parecia simples e linear, se fosse aprendido pela polarização ladrão/ vítima, deu visibilidade a uma trama de redes, que disputam e fazem alianças, conectando uma diversidade de actantes que as fabricam cotidianamente. Dessa forma, ao invés de concebermos indivíduos "bons" ou "maus" causadores de fatos, torna-se possível pensarmos os vínculos entre actantes heterogêneos que possibilitam efeitos. Bons vínculos permitem novos percursos, vivências diferenciadas e experiências inovadoras.

Deslocar o foco do "adolescente infrator" para a rede que faz-fazer possibilita outros olhares, permite repensar políticas públicas, repensar a ação dos actantes vinculados ao Estado como as escolas, as polícias e os estabelecimentos voltados para os adolescentes. Permite visualizar, ainda, que o adolescente que furta é apenas um dos actantes de uma rede extensa, que mais do que a família, vincula outros actantes como o receptador de mercadorias furtadas, a droga, o traficante, as polícias, os estabelecimentos direcionados para adolescentes autores de atos infracionais, dentre outros. Permite, também, vislumbrar a construção de outras redes, que possam tornar-se interessantes para os adolescentes e que poderiam disputar com as redes consideradas produtoras de "maus" efeitos. Pois, uma rede não é algo já dado, ela se constrói e se mantém a partir dos vínculos que unem os actantes; para se manter estável ela necessita do trabalho cotidiano dos atores e da tradução permanente dos diferentes interesses. Elementos podem ser articulados e desarticulados, fluxos podem ser estabilizados e desestabilizados.

A etnografia do evento possibilitou também detectar que a "violência" em um furto não reside apenas no ato do adolescente subtrair um bem de outra pessoa, mas também na forma agressiva da polícia abordar o adolescente, na inscrição interpretativa e redutora da história desse adolescente, nas situações difíceis enfrentadas pela sua família no cotidiano, no modo como ele é afetado pelo traficante e receptador, na forma como a mídia veicula o furto, dentre outros.

\section{Notas} ${ }^{1}$ Artigo escrito com base na pesquisa de doutorado Violências na
contemporaneidade: etnografias de redes sociotécnicas na cidade
de Chapecó (SC), realizada no período de 2004 a 2007, com
auxilio financeiro do CNPq (bolsa de doutorado), CAPES (bolsa
de doutorado no exterior) e PCDTU - UNOCHAPECÓ, apro-
vada pela Comissão de Ética em Pesquisa da UERJ (COEP)
conforme documento n ${ }^{\circ}$.004/2007.
${ }^{2}$ Também denominada de Teoria Ator-Rede e Sociologia do Ator- 
Rede, conforme Latour (2006).

${ }^{3}$ Uso a palavra violência entre aspas para referir-me à forma predominante como a mesma tem sido utilizada na contemporaneidade e problematizar a idéia de essência remetida pelo termo.

${ }^{4}$ O termo não-humano é empregado com base em Latour (2001) para referir coisas (equipamentos, materiais, artefatos de inscrição e armazenamento de dados científicos, dentre outras). Pode-se citar como exemplo de não-humanos, que se associam a humanos, em práticas violentas: a arma e a droga; na evitação da "violência" : cercas, alarmes, câmeras de vigilância; na leitura do fenômeno "violência": índices oficiais, tabelas e levantamentos estatísticos.

${ }^{5}$ Ponte que se localiza sobre o Rio Uruguai e faz a ligação entre os estados de Santa Catarina e Rio Grande do Sul.

${ }^{6}$ Mangueira utilizada para a canalização da água.

${ }^{7}$ A denominação actante seguida de uma letra (selecionada ao acaso) será empregada para denominar as pessoas entrevistadas, de forma a destacar o seu caráter de mediação tanto nos coletivos estudados, como na produção deste texto.

${ }^{8}$ Antes do século XX, o termo menoridade era utilizado como referência civil e criminal. A partir do século XX, principalmente a partir do Código de Menores, o termo surge como categoria classificatória da infância pobre, passando a carregar o preconceito para com crianças e adolescentes pobres (Bonamigo, 1998).

${ }^{9}$ Cidade vizinha de Chapecó (20 km de distância).

${ }^{10}$ Sala destinada à revisão de conteúdos dos alunos com dificuldades.

\section{Referências Bibliográficas}

Adorno, S. (2005). Le monopole étatique de la violence: le Brésil face a l'heritage occidental. In A. Peralva et al. (Org.), Dialogues franco-brésiliens sur la violence et la démocratie (pp. 149174). Paris: L'Harmattan.

Bonamigo, I. (1998). Disciplina e exclusão: processos de institucionalização das práticas de atendimento voltadas às crianças e adolescentes pobres. Chapecó, SC: Grifos.

Brasil. Estatuto da Criança e do Adolescente. (1998). Lei $n^{\circ}$. 8.069, de 13 de julho de 1990 (Coleção Saraiva de Legislação, $8^{\mathrm{a}}$ ed. atual. e ampl.). São Paulo: Saraiva.

Callon, M. (2004). Por uma nova abordagem da ciência, da inovação e do mercado. O papel das redes sócio-técnicas. In A. Parente (Org.), Tramas da rede. Porto Alegre: Sulina.

Centro de Educação Regional. (2005). Histórico do CER. Chapecó, SC.

Latour, B. (2000). Factures/fractures. De la notion de réseaux à celle d'attachement. In A. Micoud, A. \& M. Peroni (Orgs.), Ce qui nous relie (pp. 189-298). La Tour d'Aigues : Editions de l'Aube.

Latour, B. (2001). A esperança de Pandora. Bauru: EDUSC.

Latour, B. (2004). Redes que a razão desconhece: laboratórios, bibliotecas, coleções. In A. Parente (Org.), Tramas da rede (pp. 39-63). Porto Alegre: Sulina.

Latour, B. (2006). Changer de société. Refaire de la sociologie. Paris: La Découverte.

Law, J. (1999). Traduction/Trahison: Notes on ANT. Center for Science Studies, Lancaster University, Lancaster LA14YN. Acesso em janeiro, 2006, em http://www.comp.lancs.ac.uk/ sociology/papers/Law-Traduction/Trahison.pdf

Parente, A. (2004). Enredando o pensamento: redes de transformação e subjetividade. In A. Parente (Org.), Tramas da rede. Porto Alegre: Sulina.
Prefeitura Municipal de Chapecó. (2003). Política de Assistência Social e Habitação: desigualdade se combate com direitos. Chapecó, SC: Secretaria de Assistência Social e Habitação / Prefeitura Municipal de Chapecó.

Irme Salete Bonamigo é psicóloga e professora da Universidade Regional Comunitária de Chapecó (UNOCHAPECÓ), Mestre e Doutora pelo Programa de Pós Graduação em Psicologia Social da UERJ e pesquisadora do Grupo de Pesquisa sobre Violência (NESVI).Endereço para correspondência: Universidade Comunitária Regional de Chapecó - UNOCHAPECÓ. Centro de Ciências Humanas e Sociais. Avenida Senador Attílio Fontana, 591-E, Bairro Efapi - Cep: 89809-000 - Caixa Postal: 747 - Chapecó - SC. Telefone: (49) 3321-8229. bonamigo@unochapeco.edu.br

Tecendo relatos, versões e cenas: etnografia de um evento violento

Irme Salete Bonamigo

Recebido: 13/03/2008

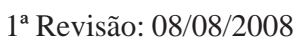

Aceite final: 18/08/2008 